Supporting Information

\title{
Simultaneous freezing of chirality and In-Out Conformation of a Macropentacyclic Cryptand by Protonation
}

Clément Bonnot, Jean-Claude Chambron* and Enrique Espinosa

Université de Bourgogne, Laboratoire d'Ingénierie Moléculaire pour la Séparation et les Applications des Gaz (CNRS, UMR 5633), 6, boulevard Gabriel, 21100 Dijon, France.

\section{Jean-Claude.Chambron@u-bourgogne.fr}

Figure S1 : VT (high temperature) ${ }^{1} \mathrm{H}-\mathrm{NMR}$ spectra $\left(500 \mathrm{MHz}, \mathrm{C}_{2} \mathrm{D}_{2} \mathrm{Cl}_{4}\right.$ ) of $\mathbf{1}$, with attribution of chemical shifts.

Figure S2 : VT (low temperature) ${ }^{1} \mathrm{H}-\mathrm{NMR}$ spectra $\left(500 \mathrm{MHz}, \mathrm{C}_{2} \mathrm{D}_{2} \mathrm{Cl}_{4}\right.$ ) of $\mathbf{1}$. Zoom on signals of $\mathrm{CH}_{3}$ of tosyl functions.

Figure S3 : Comparison of ${ }^{1} \mathrm{H}-\mathrm{NMR}$ spectra $\left(500 \mathrm{MHz}, \mathrm{CD}_{2} \mathrm{Cl}_{2}\right)$ of 1 at $210 \mathrm{~K}$ (a), with $[1-\mathrm{H}](\mathrm{TFA})$ at RT (b). Characteristic patterns of diastereotopic protons are pointed with arrows.

Figure S4 : Stacked plots of the ${ }^{1} \mathrm{H}-\mathrm{NMR}$ spectra $\left(500 \mathrm{MHz}, \mathrm{CDCl}_{3}\right.$ ) for the reaction of $\mathbf{1}$ with $\mathrm{TfOH}$ (1equiv) as a function of time. Note that at $\mathrm{t}=480 \mathrm{~min}$, there are traces of a byproduct or of an intermediate.

Figure S5 : Chemical shifts attribution of RT ${ }^{1} \mathrm{H}-\mathrm{NMR}$ spectrum $\left(500 \mathrm{MHz}, \mathrm{CDCl}_{3}\right)$ of $[\mathbf{1}-\mathrm{H}](\mathrm{OTf})$. Residual solvents peaks are marked with an asterisk.

Figure S6 : RT ${ }^{1} \mathrm{H}-\mathrm{NMR}$ spectrum (500 MHz, d $\mathrm{d}^{6}$-acetone) of [1-H]((R)-(-)BNP). (R)-(-)BNP peaks are marked with an asterisk. Split peaks are pointed with arrows.

Estimation of the relative basicity of $[1-\mathrm{H}](\mathrm{OTf})$ : Known concentrations in dry $\mathrm{CD}_{3} \mathrm{CN}$ of $[1-\mathrm{H}](\mathrm{OTf})$ and a base $\mathrm{B}$ of known $\mathrm{pK}_{\mathrm{BH}^{+}}\left(\mathrm{DABCO}^{1} \text {, [2.2.2 }\right]^{2}$, etc. $)$ were equilibrated in an NMR tube. The ratio between the concentrations of $\mathbf{1}$ and [1-H](OTf) was estimated by integration, and allowed to calculate the equilibrium constant $\mathrm{K}$ for equation (1) :

$$
[\mathbf{1}-\mathrm{H}](\mathrm{OTf})+\mathrm{B} \square \mathbf{1}+[\mathrm{BH}](\mathrm{OTf})
$$

When DABCO is used as base, $\mathrm{K} \approx 0.2$; when [2.2.2] is used as base, $\mathrm{K} \approx 2.1$.

References :

(1) Coetzee, J.F. ; Padmanabhan, G.R. J. Am. Chem. Soc. 1965, 87, 5005.

(2)(a) Leska, B. ; Pankratow, A. ; Schroeder, G. Polish J. Chem. 1994, 68, 755. (b) Koppel, I ; Koppel, J. ; Pihl, V. ; Org. React. (Tartu) 1987, 24, 387.

(3) Danil de Namor, A.F. ; Garrido Pardo, M.T. ; Muñoz, L. ; Pacheco-Tanaka, D.A. ; Sueros Velarde, F.J. ; Cabaleiro, M.C. J. Chem. Soc., Chem. Commun. 1992, 855.

There are two values in the literature for $\mathrm{pK}_{\mathrm{BH}^{+}}([2.2 .2])$ in acetonitrile $: 17.56^{2 \mathrm{a}}$ and $18.60^{2 \mathrm{~b}}$. In benzonitrile, it was found to be $18.40 .^{3}$ We find these last values in agreement with our own experiments ; in addition it is closer to the typical $\mathrm{pK}_{\mathrm{BH}^{+}}$value of a tertiary amine. 
Figure S1

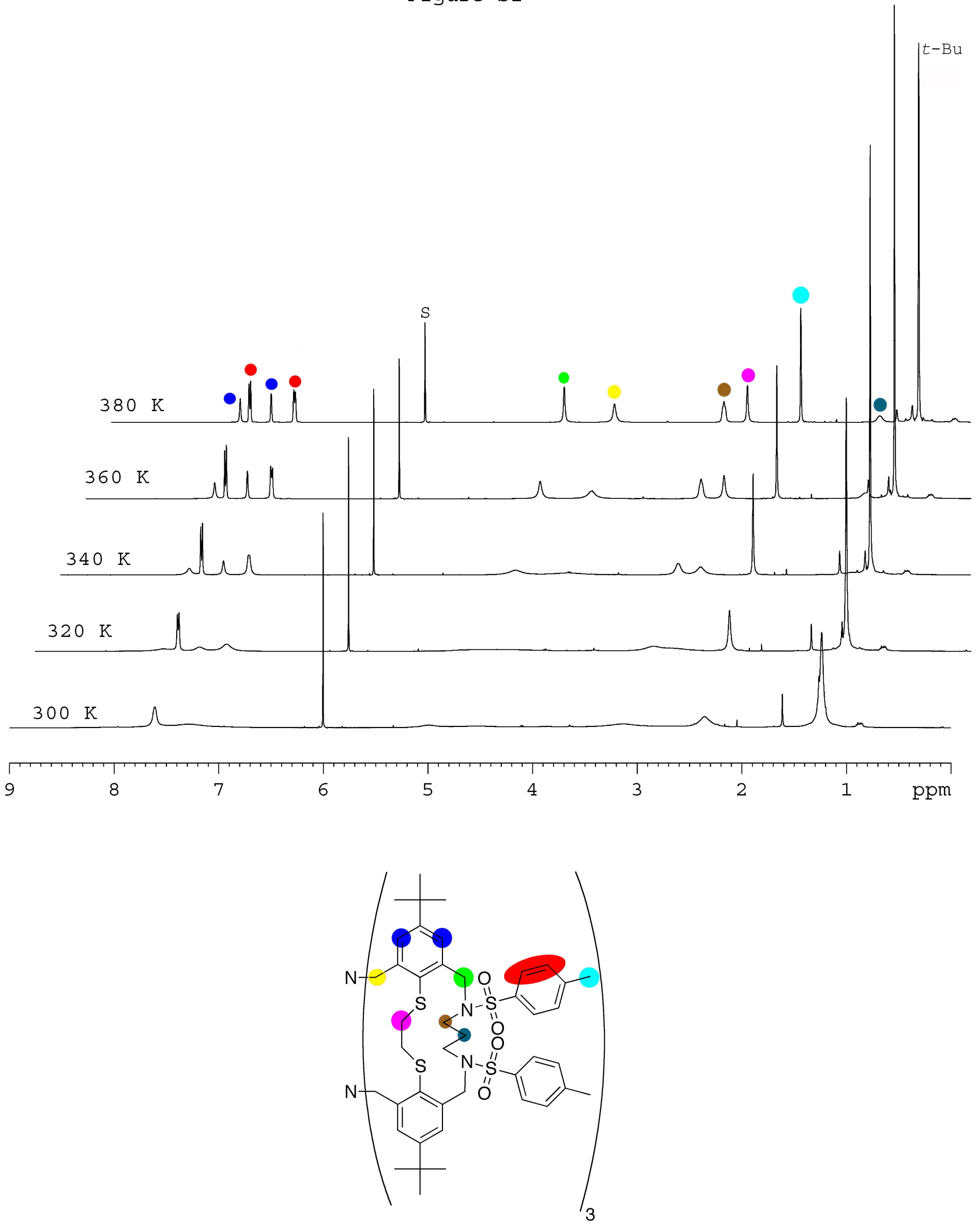


Figure S2

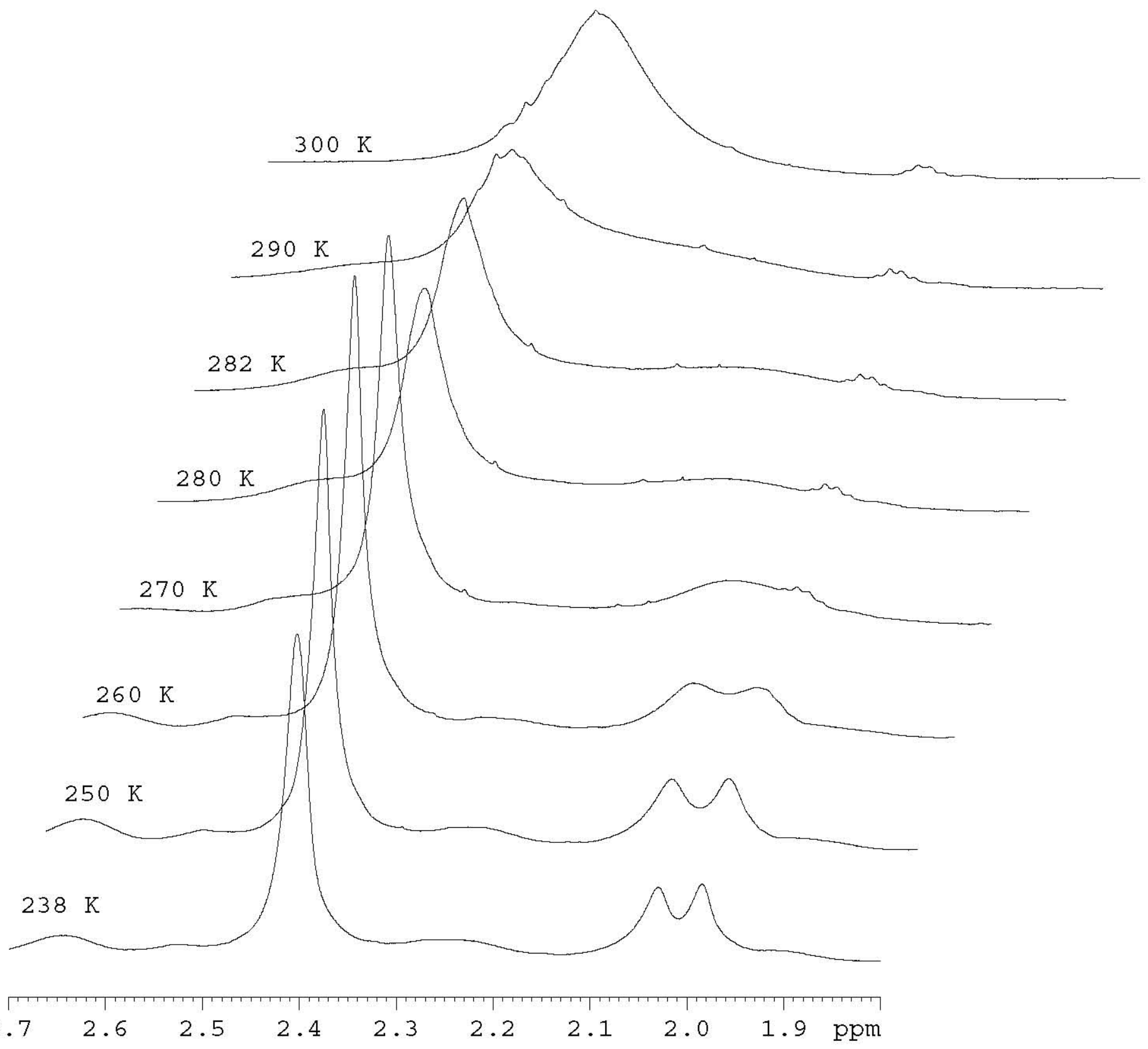




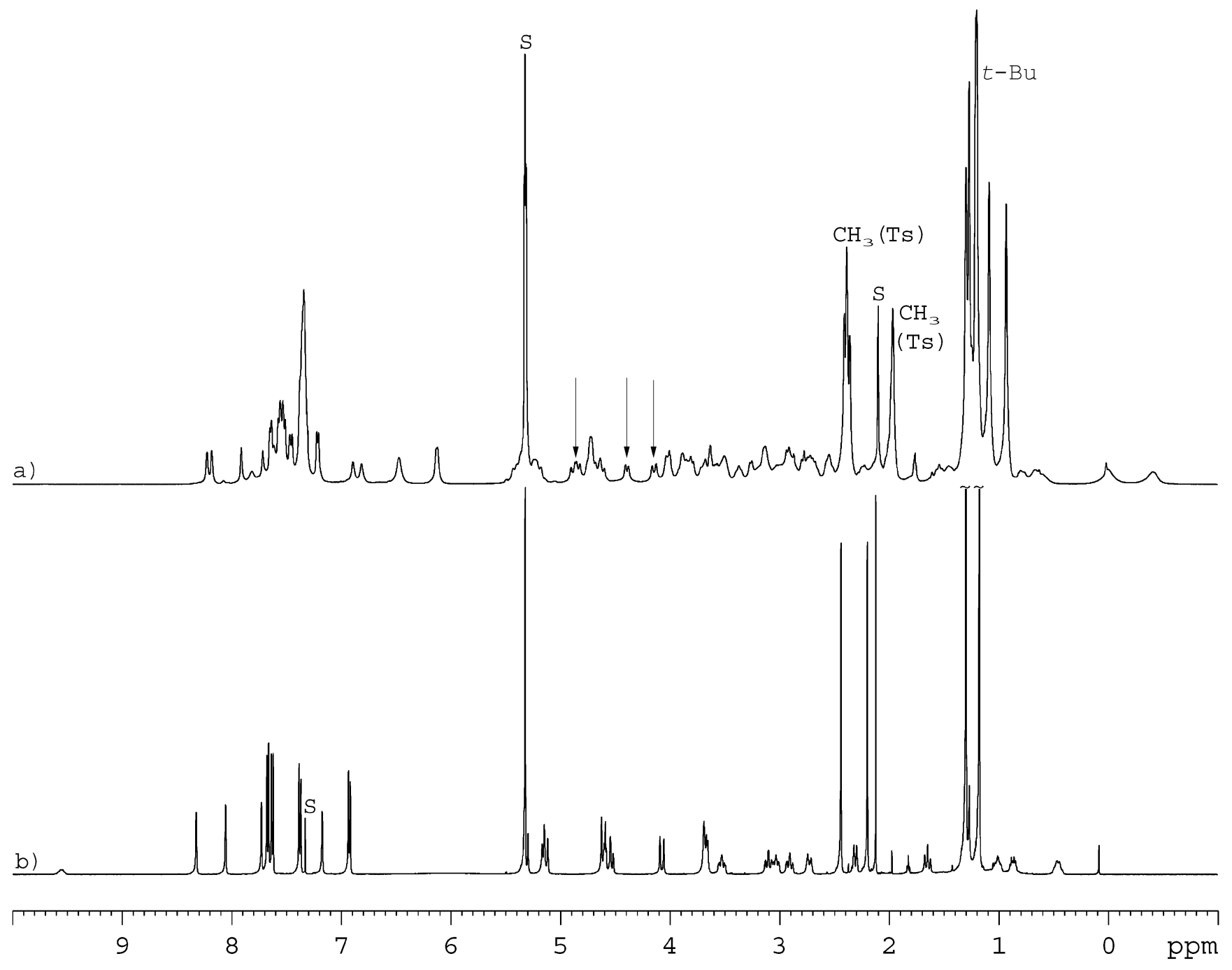




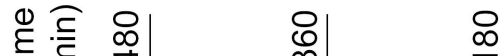




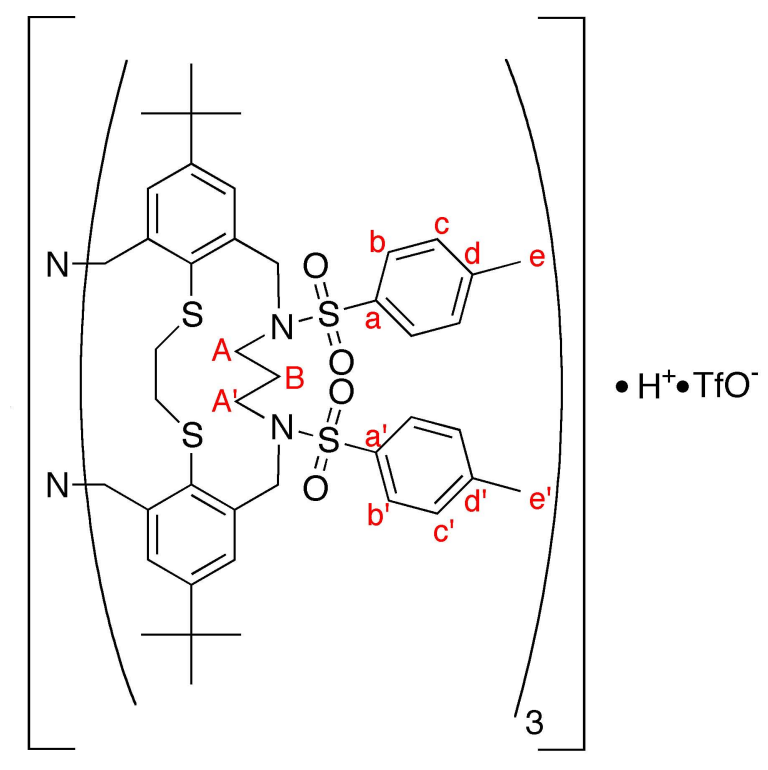

$H^{b}, H C$ and $H^{\prime} b^{\prime}, H C '$

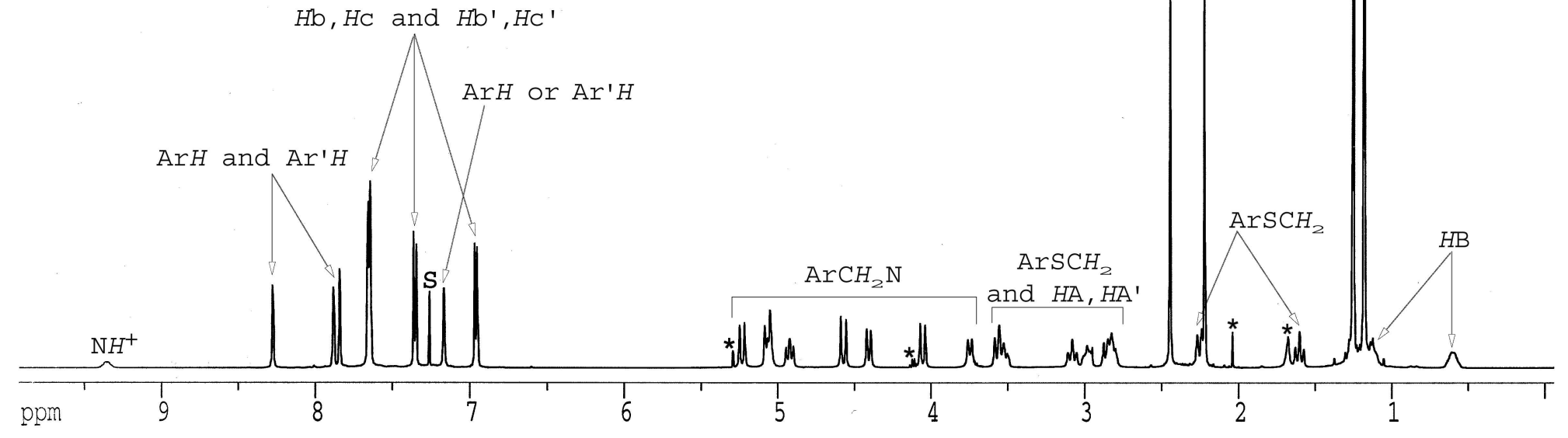


$n$

0
02
0
0
4
3
0
01
-1
-1
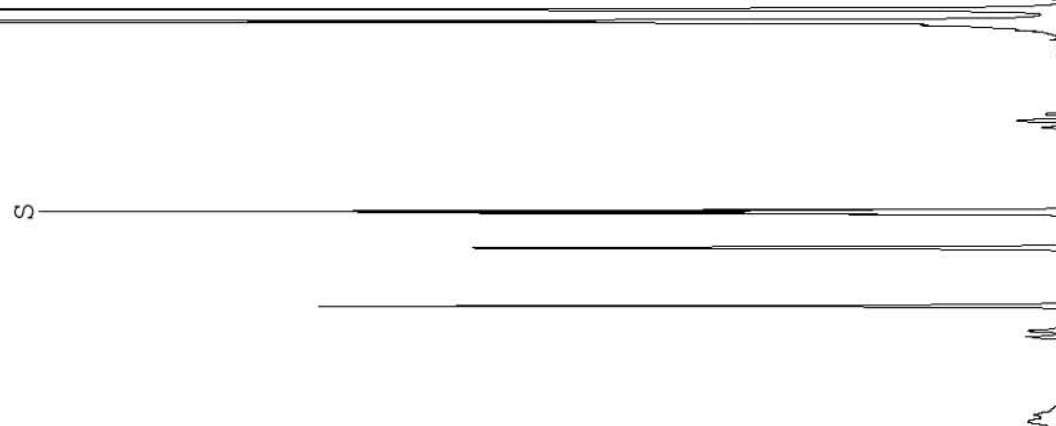
2 